\title{
PLANTÃO INSTITUCIONAL EM TEMPOS \\ DIFÍCEIS: UMA PRÁTICA PSI NO CAMPO \\ DA EDUCAÇÃO
}

\author{
Adriana Marcondes Machado \\ Yara Sayão
}

\section{O FUNCIONAMENTO DO PLANTÃO INSTITUCIONAL}

O Plantão Institucional é um dispositivo de atendimento voltado a equipes multiprofissionais, de psicólogos ou educadores que atuam em instituições públicas, nos campos da Educação, Saúde e Assistência Social. Funciona nas dependências da USP e pertence às modalidades de atendimento direto ao público que o Instituto de Psicologia da USP disponibiliza no Centro Escola do Instituto de Psicologia (CEIP). Foi criado em 1996 por Yara Sayão e Adriana Marcondes Machado, ambas psicólogas do Serviço de Psicologia Escolar, com diferentes experiências em pesquisa, atendimento direto e formação de psicólogos e educadores. A criação desse dispositivo se deu como uma resposta a depoimentos e pedidos de profissionais que participavam, na época, de cursos oferecidos pelo Serviço a professores da rede pública e que, em suas intervenções, apontavam peculiaridades vividas na escola em que trabalhavam que, muitas vezes, não cabiam nas discussões gerais dos cursos.

Essa necessidade respaldou a oferta de um espaço de escuta, discussão e reflexão das práticas a partir de uma dada instituição, com os profissionais que se disponham a ir até a USP com essa finalidade, embora, em algumas situações específicas, as psicólogas do Serviço se desloquem até a instituição (quando a dinâmica de trabalho não permite que os profissionais se ausentem). Funciona no formato de supervisão de duas horas e frequência mensal (nos atendimentos iniciais, há a possibilidade de intensificar essa frequência), com a duração média de dois anos para cada instituição'.

O trabalho de formação/intervenção realizado pelo Plantão Institucional pretende incidir, principalmente, sobre as representações, crenças e valores que se materializam nas formas de agir e pensar, permeando atividades de cuidado e educação dirigidas à infância e à adolescência. $\bigcirc$ atendimento oferece a possibilidade de explicitar e colocar em análise as representações que os profissionais têm da clientela que atendem, de seu próprio fazer, do grupo a que pertencem e da instituição na qual exercem o trabalho, das dimensões culturais da Educação, Saúde ou Assistência Social e do papel social da

\footnotetext{
I Alguns textos foram escritos pelas psicólogas do Serviço de Psicologia Escolar com relatos e reflexões sobre o trabalho realizado no Plantão Institucional: Lerner, Fonseca, Sayão e Machado, 20 I4; Sayão, 2009; e Machado, 2006.
} 
instituição em questão, responsável pela oferta de serviços que correspondem a algum direito específico de crianças e adolescentes. Visa-se, com esse trabalho, operar mudanças nas concepções e práticas utilizadas pelos profissionais que nos procuram, buscando a reflexão/compreensão dos problemas trazidos e a ampliação do repertório de estratégias utilizadas no enfrentamento dessas dificuldades, tudo com vistas à melhoria do atendimento à criança e ao adolescente. $\bigcirc$ objeto primeiro da proposta não é a dinâmica da equipe ou as relações entre seus membros para a efetivação das ações junto à clientela que atendem. Muitos grupos formulam essa necessidade ao afirmarem que as relações entre a equipe deveriam ser o foco do trabalho. Essas relações, a dinâmica constituída na realização do trabalho, fazem parte de um processo articulado com a atividade-fim da instituição e a qualidade dos serviços oferecidos à população. Isto é, na construção dos fazeres, as relações se criam. Portanto, o foco de nossa intervenção tem como eixos norteadores as práticas, o trabalho, as formas de pensar e representar os atores e os acontecimentos do cotidiano, as possibilidades e limitações de cada instituição e a expectativa pessoal e social em relação ao próprio trabalho.

A análise do trabalho dos atores concretos em uma instituição poderia nos levar a dois equívocos: que os profissionais seriam aqueles que aplicariam conhecimentos e procedimentos definidos à sua revelia ou atores concretos que poderiam romper os ditames institucionais e criar formas próprias de agir, mas, ao se atentar para os elementos que estruturam a prática institucional, percebemos que: [...] a prática dos atores concretos não é resultado, mas componente estrutural da ação das instituições; e que a prática institucional só existe encarnada na prática dos atores concretos que a constituem (Guilhon, 1978, p.70).

Os termos prática institucional, relações institucionais e instituição, utilizados neste texto, demandam um contorno para a compreensão sobre o que é uma instituição. Não se trata de um equipamento ou um local de trabalho. Definindo a instituição como "uma estrutura de práticas institucionalizadas, isto é, que tendem a se reproduzir e se legitimar" (p.72), Guilhon afirmará que a reprodução e a legitimação se estabelecem na prática dos atores concretos que constituem essa estrutura praticando-a. A instituição é um conjunto de práticas ou relações sociais concretas e sua reprodução lhe dá legitimidade. Nessa reprodução, os sentidos que os atores institucionais atribuem ao trabalho e aos outros ficam no limite entre o reconhecimento e o desconhecimento de certos aspectos da prática que exercem. Reconhecem o cotidiano como certas práticas e desconhecem a possibilidade de rupturas com o instituído. Dessa maneira, a ação dos atores perde força para agir em nome das mudanças que pretendem.

As coisas se repetem e a reprodução do instituído o legitima. Dessa maneira, as práticas, tomadas como universais, instrumentam certas hipóteses de base, como, por exemplo, a separação entre professores e alunos no campo da educação. Essas hipóteses tendem a ser trazidas como naturais, produz-se algo e o sujeito que entende esse algo naturalmente: seria natural a existência da escola e o fato de as crianças a frequentarem? Seria natural que grupos de crianças sejam divididos por faixa etária nas séries do processo de escolarização? Essas hipóteses de base é que "precisam ser interrogadas quanto às condições históricas de sua produção e reprodução" (Rodrigues e Souza, 1987). A partir 
dessa posição, pensar uma escola significa se referir às práticas de seus atores e às relações de poder e saber que se materializam nos processos formativos, na relação professor-aluno, no sistema de ensino, na definição de currículo, na concepção de desenvolvimento infantil e aprendizagem, na hierarquia, na relação dos profissionais com os familiares e responsáveis pelos alunos, nas condições de trabalho, na função da educação, nas estratégias utilizadas no cotidiano, na distribuição das verbas, na confecção das planilhas e na rotina de trabalho.

A criação do Plantão Institucional proporcionou outra forma de proceder em relação aos pedidos frequentemente dirigidos ao Serviço de Psicologia Escolar: palestras para professores, avaliação psicológica de alunos considerados difíceis, conversas com alunos e membros da direção, coordenação pedagógica ou professores da escola. Ao ofertar um espaço continuado - muito diverso de intervenções pontuais - para que a equipe trouxesse as dificuldades vividas no exercício de suas funções, a expectativa era instituir novas possibilidades de leitura e intervenção na mesma realidade que origina os pedidos, as queixas e as preocupações trazidas inicialmente. Muitas vezes, essas dificuldades são vividas pela equipe como se fossem um acidente, equívoco ou aquilo que pareceria um despropósito. Não é raro, em alguns grupos, que professoras relatem atitudes de raiva e agressividade dos alunos, como situações exteriores ao cotidiano institucional. A direção das supervisões realizadas pelo Plantão Institucional pretende esquadrinhar as situações acessando as práticas e relações sociais em que se engendram o que é trazido.

As supervisões são realizadas em equipe, a partir da interlocução com profissionais que trabalham no Serviço de Psicologia Escolar da USP², com experiência em pensar e intervir em questões que abordem institucionalmente a interface psicologia e educação e, ao mesmo tempo, pouco inteiradas do funcionamento cotidiano da instituição que demanda supervisão. Essa posição de exterioridade possibilita questionar práticas existentes e naturalizadas e de funcionamentos legitimados pela repetição, com análise e discussão pouco acuradas.

Em 20 anos de funcionamento, o Plantão Institucional atendeu profissionais de 26 municípios paulistas. A maior parte da demanda provém de escolas públicas, quase sempre das redes municipais de ensino: 21 EMEFs e 9 EMEls. Outro importante grupo profissional, com cerca de 30 equipes, que tem sido acompanhado nesses anos são as equipes multiprofissionais (psicólogos, assistentes sociais, fisioterapeutas, fonoaudiólogos, terapeutas ocupacionais, pedagogos e outros) ou apenas de psicólogos que atuam em Secretarias Municipais de Educação e outras áreas. Entre esses grupos, alguns atuam em serviços de apoio à inclusão, educação especial, acompanhamento de escolas/alunos e outros, em menor número, atuam mais proximamente ao Poder Judiciário (caso das equipes de psicólogos que atuam junto às Varas de Infância e Adolescência) ou realizam trabalhos na interface Educação/Assistência Social. Os grupos multiprofissionais (com pedagogos e professores) que atuam em instâncias intermediárias na rede municipal,

2 Atualmente, outras duas psicólogas do Serviço de Psicologia Escolar são, também, responsáveis pelos atendimentos no Plantão Institucional: Ana Beatriz Coutinho Lerner e Paula Fontana Fonseca. 
como as Diretorias Regionais de Ensino ou similares, somam 14 dos grupos já atendidos e/ou ainda em atendimento. Sete grupos atuam na Saúde, igual número de instituições de acolhimento institucional para crianças e adolescentes que foram acompanhados pelo Plantão Institucional. Atendemos, ainda, cerca de 14 instituições como ONGs ou equipamentos públicos que trabalham com atividades complementares à escola. Totalizamos, desde 1996, atendimentos a quase 120 grupos ou equipes de trabalho que atuam em instituições públicas ou oferecem gratuitamente seus serviços à população. Sempre mereceu nossa atenção especial a atuação dos psicólogos nesses grupos, dada a forte presença da Psicologia na Educação e a pertinência do Plantão Institucional ao Serviço de Psicologia Escolar do IPUSP. As reflexões realizadas a partir desses atendimentos fundamentaram a área de apoio ao ensino, já que a oferta de estágios para os alunos da graduação em Psicologia, na área de Educação, também é uma das áreas de atuação do referido Serviço.

Alguns princípios norteadores do Serviço de Psicologia Escolar e da proposta de trabalho realizada por meio do Plantão Institucional merecem explicitação:

- $\quad$ a noção de que Educação é o processo em que os adultos possibilitam, a cada criança, condições de se inserir no mundo - em particular, numa dada sociedade - e agir sobre ele. Esse processo, ao mesmo tempo que possibilita a inscrição de um sujeito em uma dada cultura, deve possibilitar também que a forma de inscrição/ação no mundo se dê de forma crítica, inventiva e produtiva. Para tanto, é necessário pensar a Educação como um processo que oferece condições aos sujeitos de analisarem criticamente a sociedade em que estão sendo inseridos e não produza apassivamento e adequação ao que se apresenta. Partimos do pressuposto de que a Educação é de interesse público, mesmo quando realizada em instituição privada. $\bigcirc$ aspecto institucional desse fazer tem espaço privilegiado em nossas intervenções;

- $\quad$ todo servidor público (ou profissional que atua em instituição cuja atividade-fim é de interesse público, como Educação, Saúde ou Assistência Social) tem, em sua ação cotidiana, uma dimensão política que implica parcela de responsabilidade em relação ao fazer daquela instituição. Essa dimensão se articula com os aspectos técnicos do trabalho que realiza, o que depende de sua formação profissional;

- há incidência da história, da política e da cultura na constituição subjetiva de cada sujeito, inclusive em supostas patologias apresentadas enquanto tais. Isso significa que os atendimentos psicológicos grupais e individuais precisam levar em conta essa constituição, que não deve ser abordada apenas em seu âmbito intrapsíquico; e

- $\quad$ as ações e práticas humanas não são naturais, aquilo que se apresenta como uma forma dada está em constante produção em um campo de relações de poder e saber. $O$ fracasso escolar, a doença mental, o abandono e a patologização dos processos de ensino e aprendizagem são produzidos. Nessa dimensão de produção, as instituições tendem a se apropriar da totalidade de objetos que são 
impalpáveis e imateriais: a Educação ficaria a cargo das escolas, dos professores e de seus saberes; a saúde ficaria a cargo da medicina, dos médicos e de seus saberes. Nesse processo de apropriação, a naturalização cega a participação da política e das relações sociais.

\section{AS QUESTÕES QUE GANHAM CONTORNO NOS GRUPOS}

Desde o início dos atendimentos aos grupos profissionais no Plantão Institucional, chama-nos a atenção o modo como as equipes apresentam o pedido da supervisão. Ficamos muito atentas às palavras que usam para formular seus pedidos ou descrever as dificuldades vividas na instituição.

Os discursos dos profissionais de uma mesma equipe são fraturados e independentes uns dos outros, possibilitando-nos levantar hipóteses de que as discussões sobre os problemas são pouco realizadas em equipe. Além disso, o tom é bastante acusatório, atribuindo a outros profissionais ou instâncias a culpa pelos problemas enfrentados e pela baixa qualidade do serviço oferecido pelo grupo. São frequentes falas do tipo: "eles são muito desorganizados, não planejam as ações", "a Secretaria funciona sem clareza de sua função, não atende a critérios técnicos e apenas a critérios políticos do tipo clientelista" ou "sempre estamos dependendo do que eles decidem, as decisões vêm sempre de cima". As afirmações dos profissionais revelam insatisfação, pois buscam realizar um trabalho que consideram de qualidade, mas não conseguem. Há produção de sofrimento e desentendimentos com os colegas de trabalho e pouco debate sobre o fazer comum; as discussões são, predominantemente, de cunho pessoal. Há falas que revelam sujeitos que não se reconhecem em seu próprio fazer, fenômeno vivido com muito constrangimento e pesar.

Em algumas situações, surgem apenas descrições dos graves problemas vividos e paralisia em relação aos possíveis enfrentamentos. Os profissionais citam impossibilidades atribuídas a outros ou ao funcionamento da própria instituição, da qual falam como se não fossem parte integrante e com a qual revelam relação de exterioridade. Em alguns grupos, escutamos pedidos diretos de solução para os problemas vividos pela equipe, revelando impedimento ou dificuldades em relação às situações trazidas e atribuição da possibilidade de enfrentamento a outros. $\bigcirc$ fato de o Plantão Institucional funcionar na USP e ser procurado também por equipes que contam com ex-alunos em seus quadros contribui para que se realize essa depositação nos profissionais responsáveis pela condução da supervisão, mas os pedidos de solução ou técnicas específicas indicam um alto grau de impotência vivida pelos profissionais, fato acompanhado de muita angústia em relação ao trabalho e relatos de situações de profissionais da equipe que adoeceram e se afastaram devido ao funcionamento considerado errático ou doentio.

As angústias, impotências e sensações de não pertencimento fizeram-nos buscar estratégias que poderiam agir na construção dessas situações. Chama-nos a atenção o pouco conhecimento, por parte dos profissionais, dos textos legais que regulam e legislam a política pública e a ação naquela área específica do Poder Público. Como pretender exercer responsabilidade compartilhada ao atuar na Educação, Saúde ou Assistência Social sem ter clareza dos direitos da criança e do adolescente, explicitados em legislação 
específica? Como almejar ampliar os estreitos horizontes de trabalho previstos para uma dada equipe ou cargo se não são exploradas as brechas existentes nos textos legais que norteiam a ação no campo? Nosso trabalho indaga sobre esse conhecimento, propondo a leitura conjunta e discussão desses textos na própria supervisão, com o intuito de explorar e dar a conhecer à equipe as diferentes possibilidades de compreensão e interpretação de um texto legal, de modo a possibilitar entradas e propostas de trabalho mais coerentes com as ideias e proposições daquele grupo.

Outro fato que nos inquieta, ao receber inicialmente as equipes de trabalho, é ouvir relatos sobre a não ocorrência de reuniões regulares da equipe - "o único espaço em que nos encontramos é aqui na supervisão" -, assim como pouquíssimos contatos com outras equipes com as quais teriam interface no fazer comum. Como exemplo, há equipes de psicólogos ou equipes multiprofissionais que atuam em Secretarias Municipais de Educação e trabalham com pouco ou nenhum contato com as equipes pedagógicas que acompanham as mesmas escolas. Esse distanciamento revela não apenas fragmentação, mas um equacionamento preocupante do trabalho que pretendem realizar, fato constatado pelas próprias equipes, mas pouco relevado pelas mesmas. Revela, também, os intensos desafios para a concretização da tão falada - e dificilmente realizada - atuação em rede, a Rede de Proteção Social necessária para a garantia de direitos a todas as crianças e adolescentes do país.

Muitas psicólogas que procuram o Plantão Institucional e atuam na Educação, em escolas de redes municipais, recebem pedidos de avaliação de alunos considerados difíceis ou supostamente portadores de algum distúrbio. A maioria dos profissionais, em especial os psicólogos, traz para a supervisão uma visão crítica do processo de patologização e medicalização muito em voga atualmente, ressaltando a individualização e depositação no aluno das dificuldades vividas pela escola em seu processo de ensino-aprendizagem. Esses mesmos profissionais, no entanto, relatam também muita dificuldade em reconhecer e instituir práticas coerentes com essa visão crítica.

Há equipes que buscam um trabalho institucional sem conseguir nomear o que isso significaria na prática. Quando interrogadas sobre isso, definem que o trabalho institucional estaria associado à "escuta dos professores" ou à "atenção às relações". Essas expressões vêm de forma esvaziada e genérica, pouco acompanhadas de reflexões, práticas e intervenções condizentes com as próprias formulações. São falas que não derivam em estratégias efetivas para agir na produção das problemáticas citadas. Algumas psicólogas que atuam em redes municipais de ensino falam, com muita ênfase, sobre o pouco ou nenhum reconhecimento, por parte dos professores da escola, da intervenção dos psicólogos no campo da Educação e, portanto, embora trabalhando em uma mesma Secretaria, as funções não chegam a objetivos comuns. Muitas vezes, percebemos que os profissionais que nos procuram pertencem apenas formalmente a uma mesma equipe de trabalho de uma Secretaria, mas não funcionam, de fato, enquanto tal no sentido de ter princípios ou objetivos comuns como grupo. Há dificuldades para criar dispositivos que possibilitem essa construção conjunta.

Entre todas as questões, as que mais nos chamam a atenção na formulação dos pedidos de supervisão são a isenção de responsabilidade e a alienação dos profissionais em relação ao trabalho que realizam cotidianamente. $\bigcirc$ próprio fato de solicitarem espontaneamente 
um pedido de supervisão (e comparecerem fora de seu horário de trabalho remunerado) nos indica que esses profissionais estão implicados nesse fazer. Muitos grupos não trazem suas preocupações e dificuldades como queixas que pretendem que sejam resolvidas, mas como questões que geram muita angústia pelo fato de não conseguirem realizar um trabalho cuja qualidade é vislumbrada, mas não alcançada.

A partir da escuta inicial dos grupos, várias questões se apresentam às psicólogas responsáveis pelos atendimentos no Plantão Institucional: quais determinantes interferem nas dificuldades vividas por esses profissionais? Como um serviço, como o Plantão Institucional, que realiza um acompanhamento longitudinal da equipe de trabalho, poderia compreender esses fenômenos e trabalhar em uma direção que pudesse oferecer elementos para que haja uma apropriação de forma mais responsável de seu próprio fazer? Como ampliar as possibilidades reflexivas da ação profissional, cuja necessidade é reconhecida, porém pouco presente no cotidiano de trabalho? De que forma intervir com essas equipes de modo a contribuir para a melhoria da qualidade dos serviços que elas prestam à população?

Interessa-nos abordar as questões relativas a pouca reflexão da prática percebida logo nos primeiros atendimentos e a questão da (des)responsabilidade dos profissionais. Para ampliar a leitura desses fenômenos, vamos recorrer primeiramente a formulações elaboradas por Franklin Leopoldo e Silva e analisar algumas ideias de Hannah Arendt sobre a questão da responsabilidade coletiva.

\section{A DETERIORAÇÃO DA REFLEXÃO NA CONTEMPORANEIDADE: UM FATO POLÍTICO}

Os desafios vividos nos atendimentos ressaltam dificuldades ligadas à possibilidade de pensar o presente. Leopoldo e Silva (200I) nos inspira a relacionar essas dificuldades à deterioração das exigências políticas da condição humana, sendo a relação entre o presente e o futuro foco de sua discussão para a compreensão dessa deterioração.

A maneira de compreendermos a relação entre presente e futuro e a forma como entendemos e vivenciamos as mudanças histórico-sociais sofreram inflexões importantes. O autor parte, para sua análise, da visão marcada no lluminismo, em que o futuro estaria atrelado à ideia de progresso e seria consequência de um presente: um futuro melhor decorreria do aprimoramento das capacidades humanas no presente, cujos avanços poderiam ser medidos. A visão de futuro controlado pelo progresso científico e tecnológico seria correspondente a um contexto de estabilidade, precisão e certeza de uma continuidade. Essas certezas do progresso entendido como passagem entre presente e futuro e de o homem e a mulher possuírem, naturalmente, domínio sobre o seu fazer eram garantidas pela possibilidade de uma consciência reflexiva que acompanharia e controlaria os processos de conhecimento. A ciência e a técnica seriam produções humanas que deveriam ter fins humanos, e essa finalidade deveria servir como controle do conhecimento e suas aplicações. Nessa visão, seria possível controlar a passagem entre o presente e o futuro com o recurso da ciência e da técnica. Nos séculos XVIII e XIX, a percepção do progresso estaria vinculada ao controle reflexivo do movimento desse progresso 
e do desenvolvimento do conhecimento. "O progresso tiraria seu sentido positivo dessa possibilidade de reflexão, e seria esse procedimento que asseguraria uma marcha firme e constante para o futuro" (Leopoldo e Silva, p.242). A possibilidade de um controle reflexivo sobre um futuro previsível forja uma máscara de ser humano como aquele com pleno domínio sobre o que faz e com condições de refletir e de agir. Como aponta Silva, não vivemos essa possibilidade de reflexão: "essa máscara caiu" (p.242), o homem não tem domínio sobre o que faz e está subordinado ao seu fazer. Estamos subordinados ao acúmulo externo de meios e produtos tecnológicos de forma irrefletida, e, portanto, as realizações do progresso escapam da reflexão.

A reflexão desaparece e a técnica - entendida como progresso técnico em que se acumulam meios autonomizados em relação aos seus fins - se torna autônoma, ocorrendo a supremacia da técnica: a tecnocracia. A autonomia no exercício da técnica se desloca: não mais os homens e mulheres são autônomos, mas a técnica é tida como autônoma.

No início do texto, o autor aponta a mudança de uma direção: o progresso entendido como passagem de um tempo presente para outro, o futuro, viveria uma inversão; o futuro deixou de estar além do presente, à nossa frente, para estar no presente. A imagem seria de uma invasão no presente pelo futuro, devido ao seu caráter de peso, opressão, e não mais de promessa de aprimoramento histórico do gênero humano.

A subordinação do homem ao acúmulo externo de meios e produtos tecnológicos passa a ser vista como progresso; um progresso técnico que tem como objetivo atingir o futuro cada vez mais rapidamente, pois o progresso passa a ser considerado da perspectiva do aprimoramento e acúmulo instrumental de meios autonomizados em relação a seus fins. Se na dimensão do presente deveria ocorrer a reflexão acerca do equilíbrio entre meios e fins, se os meios tornam-se autonomizados, o presente se esvazia.

Acelerar o ritmo: essa é a maneira técnico-instrumental de viver o tempo. Dessa forma, os projetos humanos devem abreviar o tempo fazendo do futuro conteúdo e sentido do presente. Os grupos atendidos por nós visam ao futuro quando formulam projetos, mas o sentido desse movimento deveria advir de uma relação que a consciência manteria com o presente, acessando várias determinações e buscando possibilidades de ações. Quando as exigências do futuro parecem dadas, é como se esse futuro controlasse as relações da consciência com o presente. $\bigcirc$ futuro passa a ter necessidades que seriam respondidas pelo aprimoramento da racionalidade técnica. $\bigcirc$ jogo se inverte: na educação, não importaria o lastro da tradição existente nas tensões do presente - o presente torna-se antecipação do futuro, torna-se o tempo em que deveríamos nos adaptar às chamadas exigências do futuro definidas pelos próprios rumos dos acontecimentos.

Essa mentalidade sufoca a singularidade associada à incerteza ou abertura de possibilidades na dimensão temporal do futuro: a incerteza dos projetos humanos é substituída pelos cálculos do mercado competitivo em que terá êxito e futuro o indivíduo que se subordine a essas exigências. Interessa-nos dar contorno a um processo de subjetivação em que as pessoas buscam funcionalidades e operatividades e se enfraquece a possibilidade do sujeito como agente histórico. $\bigcirc$ sujeito se tornou o mercado. Concordamos com Leopoldo e Silva quando afirma que o triunfo da tecnocracia é a abolição da política, 
mas, como ressalta o autor, esse triunfo é fato político. Portanto, não vivemos o fim da dimensão do político como se fosse uma consequência natural do domínio do econômico como uma totalidade. A naturalização dessa articulação e a ausência de reflexão geram a política de despolitização escondendo que a política é fruto da deliberação humana.

A busca por planificação eficaz de uma gestão tecnocrática do social que pretende antecipar o futuro desvaloriza o presente como lugar de deliberação sobre o futuro a partir da palavra compartilhada. A tecnoburocracia despreza a palavra e desconsidera o sujeito histórico como agente de transformação.

Essas ideias nos auxiliam a compreender a impotência e as paralisias vividas e trazidas pelos profissionais que atuam em instituições públicas que não vislumbram a dimensão política de sua intervenção e anseiam por técnicas que substituam as que conhecem e rejeitam, como, por exemplo, o psicodiagnóstico de alunos-problema. Há a expectativa de que os profissionais da universidade apresentem conhecimentos e técnicas corretas e corretivas para os problemas apresentados nas escolas e o mal-estar vivido na Educação.

No Plantão Institucional, propomos um trabalho na direção de possibilitar a ação política como intervenção legítima dos servidores públicos preocupados em elevar a qualidade do ensino oferecido pelas escolas na rede em que atuam. Muitos profissionais se mostram sensíveis e solidários com os processos de exclusão vividos por muitas crianças e adolescentes que não se enquadram nas normas preconizadas para o aluno-padrão. Ao buscarmos intervenções que possam, diferentemente dos pedidos de soluções, oferecer parâmetros para ações responsáveis dos próprios profissionais, encontramos possibilidades interessantes ao propor o exercício do pensamento crítico a partir dos problemas cotidianos da instituição, tentando, assim, superar o uso e abuso das queixas e explicações estereotipadas, repetidas e sem análise. Propomos, ainda, a busca da gênese dessas explicações na história e no passado, em que acessamos o desvelamento das visões ideologizadas que têm tanto espaço nas instituições, em especial nas educacionais.

Vemos, na contemporaneidade, a reiterada necessidade de desvalorizar o presente e suas tensões e conflitos como o espaço em que os homens deveriam deliberar sobre o futuro, ao atuar politicamente em seu sentido mais originário, compartilhando a palavra e fazendo da palavra política a expressão da responsabilidade inerente à ação histórica. Restaurar a circulação da palavra, primeiramente na horizontalidade, no interior das equipes profissionais, torna-se uma estratégia potente para o enfrentamento dos mecanismos poderosos da supremacia da técnica nos âmbitos da vida e na efetivação da política pública.

Uma das ações utilizadas na condução da supervisão consiste em produzir interrogações de modo a colocar os profissionais no lugar de sujeitos responsáveis pelo equacionamento das dificuldades vividas, parte integrante da produção daqueles acontecimentos, favorecendo, assim, o questionamento do lugar passivo e assujeitado a uma engrenagem grande e poderosa. Muitos profissionais se apresentam nessa posição, e a partir dela percebemos haver pouca ou nenhuma capacidade para intervir e modificar; ao contrário, predomina a impotência. A reflexão conjunta das diferentes crenças presentes no grupo, ao mesmo tempo que torna possível o paulatino desvelamento da complexidade das questões - trazidas pelo viés simplista e reducionista -, produz, como efeito, a potencialização do lugar e das possibilidades de ação do profissional e do grupo. 
Outra estratégia potente é a formulação de indagações e questões para as quais não há respostas certas ou erradas. A direção é estancar a repetição e a mesmice vividas e reiteradas de forma alienada no cotidiano, como, por exemplo, indagando, frente à avalanche de acusações genéricas sobre a instituição em que atuam, qual visão aquele grupo pode apresentar do que seria um atendimento de boa qualidade para aquela clientela. Nomear e explicitar a própria concepção e discutir as ideias dos colegas pode ser exercício de circulação da palavra e recuperação da dimensão do fazer compartilhado e do debate político. Nesse aspecto, reside outra de nossas inquietações: a dificuldade apresentada pela maioria das equipes que solicitam o atendimento no Plantão Institucional de atuar no serviço público de forma compartilhada, enfrentando a diversidade constitutiva dessa esfera. Para pensar esse aspecto, recorremos a Hannah Arendt (2004).

\section{A QUESTÃO DA RESPONSABILIDADE COLETIVA}

A ideia de responsabilidade compartilhada trabalhada pelo Plantão Institucional pode ser compreendida ao nos debruçarmos sobre a discussão de Hannah Arendt sobre a responsabilidade coletiva. Arendt (2004) enfatiza a distinção entre culpa e responsabilidade, indicando que há responsabilidade por coisas que outros fizeram, mas não haveria culpa por coisas que aconteceram, mas não participamos. A culpa refere-se a algo pessoal, é um ato, e não intenções ou potencialidades. Na Alemanha pós-nazista, o grito "somos todos culpados", que, a princípio, pareceu muito nobre, serviu para desculpar, em alguma medida, os que, de fato, eram culpados e demonstrar solidariedade com os malfeitores. "Quando somos todos culpados, ninguém o é" (p. 214).

Quando alguém diz sentir culpa pelos atos dos outros, teria um sentido figurado que pode obscurecer as questões reais. Somos responsáveis pelos atos de nossos pais e antepassados, assim como todo governo assume os atos de seus predecessores, mas não somos culpados, moral ou legalmente. Os dilemas morais e legais se referem ao que a pessoa faz: se alguém faz parte de um grupo criminoso, será julgado como pessoa de acordo com o que fez. Os padrões legais e morais não dizem respeito diretamente ao fato de a pessoa pertencer a um grupo.

A responsabilidade coletiva se diferencia das questões da moral e da lei, é de ordem política; nela, o mundo está no centro dos interesses, diferentemente das considerações morais da conduta humana, em cujo centro está o eu. É inerente ao fato de pertencermos a alguma comunidade, o que nenhum ato voluntário da pessoa pode dissolver, pois nenhum homem pode viver sem pertencer a uma comunidade. Esse é seu caráter político. A exceção a isso é representada pela situação dos refugiados e sem pátria que não podem ser politicamente responsabilizáveis e, como sustenta Arendt, essa inocência os condena a uma posição de alheamento.

Ao sermos membro de uma comunidade ou um grupo, somos considerados responsáveis por coisas das quais não participamos, mas que foram feitas em nome dessa comunidade ou grupo. $\bigcirc$ uso desse verbo, participar, mostra sua complexidade na argumentação de Arendt, ao tecer considerações sobre o que seria a não participação em diferentes formas de governo. Em formas de governo de tirania, não se pode considerar 
que a não participação seja uma questão de escolha, pois é esperada e exigida. Em países livres, a não participação pode ser uma forma de resistência e, desde que haja liberdade para associação das pessoas e esperança de que essa resistência provoque mudanças, ela será política. Arendt exemplifica com o caso dos que se recusaram a ser recrutados para a guerra do Vietnã. Nessa situação, a não participação é política.

Por que a dificuldade em apropriar-se da responsabilidade coletiva, assumir as consequências por coisas que não fizemos? O que enfraquece a faculdade de agir no mundo, política por excelência?

Em A condição humana, Arendt (1997) discute que o advento da era moderna trouxe a eliminação da separação entre as esferas pública e privada que ocorria na Grécia antiga. Sem a mediação da esfera pública, o interesse individual se sobrepõe ao coletivo, o que redunda em aumento de vontade de consumo e crescimento do vazio existencial. A consideração de que nossa vida é levada entre os semelhantes e que a política só pode ser tornada real em uma das muitas formas de comunidade humana nos indicam que o isolamento tem profunda relação com a impotência quanto à capacidade de assumir a responsabilidade coletiva.

A proposição de a dimensão política ser atribuída imediatamente ao coletivo, do qual necessariamente todos fazemos parte, é particularmente importante para pensar a postura de muitos profissionais que se sentem alheios ou assujeitados ao funcionamento da máquina estatal ou institucional em que atuam e não percebem sua parcela de responsabilidade nas ações desenvolvidas pela Secretaria em que trabalham. Também ressaltamos a importância de os profissionais que atuam com políticas públicas entrarem em contato com o peso que podem ter suas palavras e seus atos no exercício do serviço público, um dos parcos redutos de coletividade na contemporaneidade.

No Plantão Institucional, utilizamos, como estratégia de intervenção, interrogações sobre a posição que esses profissionais assumem em relação às ações implementadas em sua área de atuação, que são expressões da política pública vigente na área, da qual, em alguma medida, todos participam.

Já ouvimos relatos em que a atitude de resistência ou reivindicação de certo grupo profissional teve importante papel na mudança política que se pretendia implantar. Acompanhamos por vários anos um grupo de professores de uma escola pública que contava com uma equipe de direção muito ausente e que, mesmo assim, realizava importantes discussões e mudanças nas práticas pedagógicas no sentido de melhorar a qualidade do ensino na escola. Acontecimentos como esse questionam, por si só, a percepção de muitos profissionais - psicólogos, pedagogos, assistentes sociais e outros - de que "não adianta fazer oposição ou questionar as decisões da Secretaria" ou "as mudanças só acontecem a partir da equipe de direção". Também discutimos nas supervisões o modo como isso pode ser feito, há imensas diferenças - em especial nos efeitos provocados - entre denúncias gerais pouco fundamentadas e propostas concretas de ação apoiadas em argumentos consistentes do próprio trabalho e articuladas com os direitos dos usuários dos serviços públicos - direitos que se constituem em deveres para o Estado.

Muitas vezes nos deparamos com críticas formuladas por uma equipe que, ao serem analisadas, se mostram estar mais a serviço de conflitos pessoais do que dirigidas 
à execução de uma política de Estado. É necessário que se aponte a distinção desses aspectos e se favoreça a elaboração de críticas que se sustentem do ponto de vista técnico-político e sejam argumentativas na direção da garantia de direitos e da qualidade do serviço oferecido à população.

A partir da concepção de responsabilidade coletiva formulada por Hannah Arendt, articulamos essa proposição com a importância da responsabilidade compartilhada, inerente ao trabalho em uma instituição pública ou de interesse público, como o caso da Educação. Quando dizemos compartilhada, pensamos, em primeiro lugar, na questão das múltiplas instâncias, processos e atores institucionais cuja ação depende e se complementa com a ação dos demais, de forma a não ser possível isolar um único responsável pelo resultado obtido. Em relação ao ensino, essa proposição se opõe à antiga, porém ainda presente, noção de que o professor, quando fecha sua sala de aula, teria total responsabilidade e poder sobre o que acontece naquela situação didática.

Os textos e reflexões de Demerval Saviani e Maria Helena Patto nos mostram a complexidade da questão de políticas públicas na Educação: mesmo em uma situação em que um profissional da Educação vive algo como particular, também comparece, sempre, de muitas maneiras, a formulação, a implementação e a execução da política educacional. São muitos os atores, aparentemente invisíveis, cuja ação também interfere na realização das atividades didáticas, como uma aula - rotina do cotidiano das escolas, públicas ou privadas.

No Plantão Institucional trabalhamos a questão do compartilhamento de responsabilidade na realização de qualquer trabalho no serviço público - e, portanto, da necessidade de cada profissional assumir sua parcela de responsabilidade não apenas pelo trabalho técnico que realiza, mas também em relação ao aspecto político de sua atuação no interior do órgão em que atua - por meio de estratégias que favoreçam a explicitação e o desvelamento de todas as instâncias envolvidas no trato da coisa pública. Por isso, convidamos a equipe que nos procura a detectar e nomear os atores institucionais que também concorrem não só para o planejamento, mas também para a execução da política na qual a equipe está envolvida, o que ocupa vários de nossos encontros e impulsiona a utilizar diferentes manejos grupais.

Uma estratégia largamente utilizada em supervisões e reuniões de equipes que contam com um profissional psi é a discussão de caso. Trata-se de situação em que se aprofundam e ao mesmo tempo se alargam o olhar e a compreensão sobre uma criança ou adolescente atendidos, seus familiares e responsáveis, com vistas a ampliar/potencializar as possibilidades de intervenção do profissional responsável pelo atendimento específico.

No Plantão Institucional, discutimos cenas, situações específicas e os casos. Nas discussões de casos trazidos pelas profissionais, vamos para além dos aspectos individuais, intrapsíquicos e singulares pertinentes a cada criança ou adolescente e família atendidos, indicando os aspectos que, a princípio invisíveis, são determinantes para o funcionamento daquela equipe e o consequente atendimento das demandas da criança ou adolescente em questão. De que forma se dá o acolhimento inicial daquela criança ou adolescente na instituição? Quais são as diferenças internas, tanto de escolhas teórico-técnicas quanto de postura no trabalho, e como isso opera na decisão e definição das ações dos profissionais? Como se estabelece a relação com a chefia imediata e outras instâncias de poder que perpassam a instituição? Essas são algumas questões que raramente comparecem 
espontaneamente por parte dos profissionais que procuram o Plantão Institucional, mas é muito importante que sejam explicitadas e discutidas abertamente pelos participantes da equipe.

\section{CONSIDERAÇÕES FINAIS}

Com grupos acompanhados por um longo período - 4 a 6 anos -, pudemos notar a paulatina introjeção de uma maneira de pensar, um modo de produzir conhecimento compartilhado. Exercitamos, nas supervisões do Plantão Institucional, a responsabilização pelo que lá se produz. O próprio Plantão Institucional é, em vários momentos, colocado em análise. $\bigcirc$ fato de as discussões serem mediadas pelas profissionais do Serviço de Psicologia Escolar de maneira a se favorecer o acesso aos aspectos institucionais confere segurança à equipe para o fortalecimento da dimensão grupal.

Compreendemos que acessar a dimensão institucional das questões trazidas implica resgatar a trajetória da política pública e as funções históricas da instituição da qual participam os grupos que nos procuram, discutir as relações que aquele grupo mantém com outras instâncias de poder, analisar as práticas cotidianas na articulação com os efeitos que produzem, fortalecer o caráter político e comum do trabalho, relacionar o funcionamento do cotidiano do trabalho com as dificuldades muitas vezes depositadas fora dele e ampliar os debates e discussões sobre as questões trazidas pelos profissionais, buscando os argumentos técnico-políticos que possam embasar as deliberações do grupo.

As experiências vividas nos atendimentos do Plantão Institucional permitiram que o Serviço de Psicologia Escolar expandisse a abrangência de suas ações, atingindo um maior número de profissionais e instituições e estendendo suas intervenções para instituições que trabalham com a interface da Educação com a Saúde e a Assistência Social. Já desenvolvíamos reflexões e ações em diferentes instituições no sentido de ampliar o campo de análise do que tradicionalmente nos era apresentado: crianças e jovens com problemas e dificuldades no processo de escolarização.

Nossa compreensão sobre os fenômenos trazidos pelos grupos atendidos - como algo sempre em constante produção e constituídos por práticas que se engendram em relações de poder e saber - demanda levar em conta que os saberes e as relações de poder em que estamos submersos também estão presentes nas ações que inventamos. Manter o Plantão Institucional como dispositivo de enfrentamento em relação à produção de assujeitamento necessita de constante discussão sobre os grupos atendidos em nossa equipe. Cada grupo é atendido por apenas uma profissional da equipe (alguns grupos são atendidos por uma dupla) e não é raro, nas reuniões da equipe do Serviço de Psicologia Escolar em que abordamos o trabalho realizado no Plantão Institucional, nos darmos conta de situações que passaram despercebidas pela profissional responsável do Serviço pelo atendimento efetuado a certo grupo. Essa possibilidade de um olhar estrangeiro - fora de nós - e compartilhar as reflexões com quem não é responsável pelo atendimento direto dilata a possibilidade de estranhar o que se faz e isso é imprescindível para a desconstrução de processos de naturalização. 


\section{REFERÊNCIAS BIBLIOGRÁFICAS}

Arendt, H. (2004) Responsabilidade e julgamento. São Paulo: Companhia da Letras. (1997). A Condição Humana. Rio de Janeiro: Forense Universitária.

Guilhon Albuquerque, J. F. (1978). Metáforas da desordem: o contexto social da doença mental. Rio de Janeiro: Paz e Terra.

Lerner, A. B. C., Fonseca, P. F., Sayão, Y., \& Machado, A. M. (20|4). Plantão institucional: uma modalidade de intervenção face ao mal-estar contemporâneo na educação. Revista Estilos da Clínica, 19(1), 199-208.

Leopoldo e Silva, F. (200 I). O mundo vazio: sobre a ausência da política no contexto contemporâneo. In Accioly, D., \& Marrach, S. A. Maurício Tragtemberg. Uma vida para as Ciências Humanas. Araraquara: UNESP e FAPESP.

Machado, A. M. (2006). Plantão Institucional: um dispositivo criador In Machado, A. M., Fernandes, A., \& Rocha, M. Novos Possíveis no encontro da Psicologia com a Educação (v. I). São Paulo: Casa do Psicólogo.

Patto, M.H.S. (1990). A produção do fracasso Escolar: histórias de submissão e rebeldia. São Paulo: T.A. Queiroz.

Rodrigues, H. B. C, \& Souza, V. L. B. ( 1987). A análise Institucional e a profissionalização do psicólogo. In Saidon, O., \& Kamkhagi, V.R. Análise Institucional no Brasil: favela, hospício, escola, FUNABEM. Rio de Janeiro: Espaço e Tempo.

Saviani, D. (1985). Escola e Democracia: teorias da educação, curvatura da vara, onze teses sobre educação e política. São Paulo: Cortêz.

Sayão, Y. (2009). Plantão Institucional: uma prática de atendimento psicológico entre os campos da Saúde e da Educação. ANAIS I Congresso Luso-Brasileiro de Psicologia da Saúde, Cidade de Faro, Portugal. Recuperado de <mww.eventos.ualg.pt/cips $\geq$. 